\title{
Brazilian recommendations on the safety and effectiveness of the yellow fever vaccination in patients with chronic immune-mediated inflammatory diseases
}

Gecilmara Salviato Pileggi ${ }^{1,34^{*}}$ (D), Licia Maria Henrique Da Mota², Adriana Maria Kakehasi ${ }^{3}$, Alexandre Wagner De Souza ${ }^{4}$, Aline Rocha ${ }^{5}$, Ana Karla Guedes de Melo ${ }^{6}$, Caroline Araujo M. da Fonte ${ }^{7}$, Cecilia Bortoletto ${ }^{8}$, Claiton Viegas Brenol ${ }^{9}$, Claudia Diniz Lopes Marques ${ }^{10}$, Cyrla Zaltman ${ }^{11}$, Eduardo Ferreira Borba ${ }^{12}$, Enio Ribeiro Reis ${ }^{13}$, Eutilia Andrade Medeiros Freire ${ }^{14}$, Evandro Mendes Klumb ${ }^{14}$, Georges Basile Christopoulos ${ }^{15}$, leda Maria M. Laurindo ${ }^{16}$, Isabella Ballalai ${ }^{17}$, Izaias Pereira Da Costa ${ }^{18}$, Lessandra Michelin ${ }^{19}$, Lilian David de Azevêdo Valadares ${ }^{20}$, Liliana Andrade Chebli ${ }^{21}$, Marcus Lacerda ${ }^{22}$, Maria Amazile Ferreira Toscano ${ }^{23}$, Michel Alexandre Yazbek ${ }^{24}$, Rejane Maria R. De Abreu Vieira ${ }^{25}$, Renata Magalhães ${ }^{26}$, Renato Kfouri ${ }^{27}$, Rosana Richtmann ${ }^{28}$, Selma Da Costa Silva Merenlender ${ }^{29}$, Valeria Valim ${ }^{30}$, Marcos Renato De Assis ${ }^{31}$, Sergio Candido Kowalski ${ }^{32}$ and Virginia Fernandes Moça Trevisani ${ }^{33}$

\section{Abstract}

Background: In Brazil, we are facing an alarming epidemic scenario of Yellow fever (YF), which is reaching the most populous areas of the country in unvaccinated people. Vaccination is the only effective tool to prevent YF. In special situations, such as patients with chronic immune-mediated inflammatory diseases (CIMID), undergoing immunosuppressive therapy, as a higher risk of severe adverse events may occur, assessment of the risk-benefit ratio of the yellow fever vaccine (YFV) should be performed on an individual level.

Main body of the abstract: Faced with the scarcity of specific orientation on YFV for this special group of patients, the Brazilian Rheumatology Society (BRS) endorsed a project aiming the development of individualized YFV recommendations for patients with CIMID, guided by questions addressed by both medical professionals and patients, followed an internationally validated methodology (GIN-McMaster Guideline Development). Firstly, a systematic review was carried out and an expert panel formed to take part of the decision process, comprising BRS clinical practitioners, as well as individuals from the Brazilian Dermatology Society (BDS), Brazilian Inflammatory Bowel Diseases Study Group (GEDIIB), and specialists on infectious diseases and vaccination (from Tropical Medicine, Infectious Diseases and Immunizations National Societies); in addition, two representatives of patient groups were included as members of the panel. When the quality of the evidence was low or there was a lack of evidence to determine the recommendations, the decisions were based on the expert opinion panel and a Delphi approach was performed. A recommendation was accepted upon achieving $\geq 80 \%$ agreement among the panel, including the patient representatives. As a result, eight recommendations were developed regarding the (Continued on next page)

\footnotetext{
* Correspondence: gecilmara@gmail.com

'SBR. Faculdade de Ciências da Saúde de Barretos - FACISB, Barretos, São Paulo, Brazil

${ }^{34}$ School of Medical Science Barretos- FACISB, Avenue Masonic Lodge Renovadora 68, No. 100 - Airport Neighborhood, Barretos/SP 14785-002, Brazil

Full list of author information is available at the end of the article
}

(C) The Author(s). 2019 Open Access This article is distributed under the terms of the Creative Commons Attribution 4.0 International License (http://creativecommons.org/licenses/by/4.0/), which permits unrestricted use, distribution, and reproduction in any medium, provided you give appropriate credit to the original author(s) and the source, provide a link to the Creative Commons license, and indicate if changes were made. The Creative Commons Public Domain Dedication waiver (http://creativecommons.org/publicdomain/zero/1.0/) applies to the data made available in this article, unless otherwise stated. 
(Continued from previous page)

safety of YFV in patients with CIMID, considering the immunosuppression degree conferred by the treatment used. It was not possible to establish recommendations on the effectiveness of YFV in these patients as there is no consistent evidence to support these recommendations.

Conclusion: This paper approaches a real need, assessed by clinicians and patient care groups, to address specific questions on the management of YFV in patients with CIMID living or traveling to YF endemic areas, involving specialists from many areas together with patients, and might have global applicability, contributing to and supporting vaccination practices. We recommended a shared decision-making approach on taking or not the YFV.

\section{Background}

\section{Yellow fever: Disease and vaccine}

Yellow fever (YF) is an infectious zoonotic disease caused by an RNA arbovirus, belonging to the family Flaviviridae, transmitted by hematophagous insects, especially of the genera Aedes and Haemagogus. In Brazil, the main sylvatic cycle of transmission involves mostly Haemagogus mosquitos. The disease is both, endemic and epidemic, in tropical regions of South America and Africa, and its clinical spectrum is highly variable, ranging from asymptomatic to severe disease, with a $50 \%$ mortality risk $[1,2]$.

In Brazil, although YF is endemic in the North and Central West regions, it has become epidemic outside the Legal Amazon in the last five years. The YF transmission cycle occasionally re-emerges and, in the last decade, an increase in viral circulation has been observed throughout the country [3, 4]. From July 2016 to March 2017, 691 cases and 220 deaths were confirmed; an increase was noticed during the same period of the following year, when the records increased to 1127 cases and 328 deaths (http://portalms.saude.gov.br/boletim-epidemiologico, access December, 2018).

Vaccination is the only effective measure to prevent YF. The rapid recognition of disease outbreaks in high-risk areas, followed by the vaccination of 60 to $80 \%$ of the population is crucial to prevent epidemics [5].

The YFV is composed of an attenuated live virus, specific pathogen free (SPF) strain 17D or equivalent, cultivated in chicken embryo eggs, and has been used for the prevention of the disease since 1937. It is considered highly immunogenic, capable of immunizing 95 to $99 \%$ of adults and approximately $90 \%$ of infants ( $<2$ years) one week after application $[3,6,7]$. However, on the other hand, the YFV is related to a potential risk of inducing an adverse event following vaccination (AEFV) [8].

According to the World Health Organization (WHO), an AEFV is defined as any harmful medical occurrence after vaccination, classified as local or systemic, even without a clear causal relationship traced back to the vaccine. In general, AEFVs are mild and transitory. They generally occur three to seven days after vaccination and usually last no longer than three to seven days. Local manifestations (pain, erythema, and induration at the injection site) or systemic manifestations, such as malaise, tiredness, low fever, mild headache or myalgia may occur $[3,6,7]$.

The major concern regarding an AEFV is when it is reported as a severe adverse event ( $\mathrm{SAE}$ ), characterized by hospitalization required for at least $24 \mathrm{~h}$, significant dysfunction, and/or persistent secondary or congenital abnormality and even death or risk of death [9]. Although rare, SAEs can occur, particularly post-primary vaccination, mainly during immunization campaigns in areas with no prior vaccine recommendation $[10,11]$. SAEs related to the YFV are extremely rare and the risk of dying from YF is considered higher than vaccinationassociated risks [5].

In Brazil, there are two vaccines available, derived from the same strain, with very similar and comparable response profiles and reactogenicity - YFV 17DD (Biomanguinhos $\odot$ ) and 17D-204 (Sanofi Pasteur@) $[3,6,7,12]$. The current Brazilian immunization schedule recommends a single subcutaneous $0.5 \mathrm{ml}$ dose at nine months of age [6] and is contraindicated in some groups, as follows $[3,5,13]$ :

- infants younger than nine months for routine immunization or younger than six months during an epidemic;

- pregnant women or breastfeeding children under six months of age, except during YF outbreaks, when the risk of infection is high;

- severe allergies to egg protein;

- history of severe adverse reactions to previous doses;

- organ transplantation;

- previous history of thymus disease (myasthenia gravis, thymoma, thymus absence or surgical removal);

- severe immunodeficiency of any nature.

The most serious SAE related to YFV is associated with viscerotropic disease (YEL-AVD), an acute post-vaccination dysfunction that usually appears one to four weeks after vaccination, with clinical manifestations 
ranging from a mild multisystem disease to multiple organ failure and death. Virological and pathological findings during necropsies of vaccinated patients showed the replication and uncontrolled dissemination of the 17D or 17DD virus. The initial symptoms are nonspecific, similar to YF manifestations. The most serious condition associated with YEL-AVD is characterized by hypotension, hemorrhage, and acute renal and respiratory failure, with an overall case-fatality rate of approximately $50 \%[14,15]$.

According to Staples et al. (2017), at least 100 cases of YEL-AVD had been reported worldwide and none were reported after revaccination until February 2017. In the United States, the incidence of YEL-AVD is 0.25-0.4/ 100,000 doses and in Brazil, 21 cases were reported from 2007 to 2012, at a rate of 0.04 cases per 100,000 administered doses. In 2009, during the vaccination campaign in the State of São Paulo, 0.31 cases per 100,000 doses applied were observed, and in Rio Grande do Sul, the frequency observed was 0.11 per 100,000 doses applied [16].

Another SAE is the yellow fever vaccine-associated neurotropic disease (YEL-AND), which although not related to death, can cause hypersensitive reactions, neurological manifestations (encephalitis, meningitis, Guillain-Barré syndrome, etc.), and autoimmune diseases, involving the central and peripheral nervous system $[9,17]$.

A single-dose vaccination has been implemented since April 2017, however due to conflicting results on immunity in long-term YFV studies it is still under debate among vaccination experts $[6,18-21]$.

According to the WHO, the use of fractional-dose YFV is a good strategy to avoid disease outbreaks as this strategy rapidly increases vaccination coverage in areas of risk [22]. Recently in Brazil, the Ministry of Health started a campaign using YFV fractionated-dose due to the current epidemic quickly spreading over the most populous states.

Due to the current epidemiological setting, the vaccination against the YF virus will be extended and recommended across the country. It is intended to be gradually incorporated as part of the basic vaccination schedule in all Brazilian States from July 2018 [4].

Yellow fever vaccine: Assessment of the immunogenicity

YFV is one of the most immunogenic vaccines. The highly effective and long-lasting immunity caused by 17D makes it an important research target for the development of vaccines against related viruses and for understanding the attenuation and immunological induction processes for highly effective vaccines in general [23]. Studies have demonstrated that humoral immunity is a primary protective element in previously exposed individuals, and a single vaccine may provide protection against global strains of the YF virus $[18,23]$. Approximately $90 \%$ of $17 \mathrm{D}$ - immunized individuals are shown to be producing neutralizing antibodies on the tenth day after vaccination, and almost $100 \%$ are doing so by day 30 [21].

The post-immunization humoral responses to YFV can be measured by the plaque reduction neutralization test (PRNT). This is the gold standard correlation of protection method, which is considered when more than $80 \%$ of virus neutralization at 1:10 dilution is detected in the serum. The micro-PRTN90 has a sensitivity of $100 \%$ and specificity of $94.7 \%$ for the yellow fever virus [24].

Other methods, such as the Indirect Immunofluorescence Test (IFA), used to evaluate IgG antibodies, present false positives with various viruses of the Flaviviridae family, and although highly sensitive, it does not reach the specificity of the PRNT. The specificity of these tests is impaired in patients with Dengue fever history [25]. Thus, the neutralizing antibodies remain accepted as a correlate of protection against the YF virus.

To date, there is no other adequate method to evaluate the response to YFV in humans besides neutralizing antibodies. Nevertheless, new alternatives based on the complex modulation of innate immune cytokines induced by YFV are being studied [26]. In addition, CD4+ and CD8+ T cells strongly respond to $17 \mathrm{D}$, with $\mathrm{CD} 4+\mathrm{T}$ reaching their highest level between seven and 14 days and CD8+ T between 14 and 30 days after vaccination. These cells slowly decline over time, but remain detectable for more than 25 years, while another group of self-renewing and highly responsive 17D-specific memory cells remains stable during the same 25-year period. Complementary studies in humans are required regarding cytokine and $\mathrm{CD} 4+$ and CD8+ $\mathrm{T}$ cell counts in order to assess their real benefit as a vaccine response marker [27].

Studies published to date (WHO, ACIP, and CDC) have shown that approximately $88 \%$ of healthy individuals remain seropositive for more than ten years after the YFV [20]. On the other hand, Brazilian studies have demonstrated a fall in protection after 5-10 years in some groups [6, 24]. It is crucial to obtain further understanding about the YFV immunogenicity in patients with CIMID, particularly in Brazil, since it is an endemic area with frequent outbreaks of the disease.

\section{Yellow fever vaccine in specific situations of immunosuppression}

In some situations, there is a higher risk of AEFV, and it is important to evaluate the risk-benefit ratio on an individual basis. In cases of moderate to severe acute febrile illnesses, postponement of the vaccine is recommended until resolution of the condition. Blood or organ donors should wait for four weeks after vaccination before donating; the immunosuppression degree of patients with CIMID, undergoing immunosuppressive therapy, 
should be established in order to evaluate the safety of receiving the YFV [3].

The CIMID concept is used to collectively describe a group of heterogeneous diseases that share common inflammatory pathways and deregulation in the immune system. These are responsible for chronic inflammation, such as rheumatoid arthritis (RA), ankylosing spondylitis (AS), psoriasis, psoriatic arthritis (PsoA), multiple sclerosis (MS), systemic lupus erythematosus (SLE), and inflammatory bowel diseases (IBD), such as Crohn's disease and ulcerative colitis [28]. These diseases affect approximately $5-8 \%$ of the population and cause significant morbidity, mortality, and a high risk of infection [29].

The treatment of these diseases is based mainly on immunosuppressive or immunomodulatory agents to control chronic inflammation. The use of these medications, with different mechanisms of action, besides changes in the immune system inherent in the underlying disease, lead to variable degrees of immunosuppression and, consequently, increase susceptibility to infections, which is considered the major cause of morbidity and mortality in this population [30]. As a result, the immunogenicity of vaccines may be reduced. Furthermore, the administration of live attenuated vaccines (LAV) bears the potential risk of invasive infection with the attenuated vaccine strain and should generally be avoided in patients under immunosuppressive therapy; this being the reason why these vaccines are generally contraindicated in this population [31,32].

According to the Brazilian Ministry of Health, the recommendation for YF vaccination is based on the routine immunization of the population exposed to the virus, residents or subjects travelling to endemic regions, in the absence of contraindications. There are still some controversial issues regarding contraindication, and they require caution, as well as the elderly population (over sixty years old), and patients with different immunosuppression degrees [3].

For patients with CIMID, it is essential to take into account the risk of (rare) post-vaccination adverse events and the protection provided by a highly effective vaccine against a potentially lethal illness without specific treatment. When evaluating the risk of severe AEFVs, we should consider the underlying disease, its severity, level of activity, and immunosuppression degree. At the same time, we should consider the risk of contracting the YF virus in areas of vaccine recommendation [15, 33, 34].

It is important to emphasize that none of the review articles or consensus formed by the panels of experts have established specific recommendations or absolute contraindications against the indication of LAV in patients with CIMID, considering the particular differences between the diseases and their treatment. Based on the knowledge that the only effective measure to prevent YF is vaccination, and that many immunocompromised patients have been inadvertently vaccinated without presenting an SAE [35], these panels of specialists agree that there is no absolute contraindication for YFV in this setting and the risk and benefits should be considered individually.

In this context, management should be individualized, according to the underlying disease, medications used and their doses, replication capacity of the attenuated vaccine virus, and risk of infection. Risks related to LAV potentially involve viral replication capability (elevated with the YFV agent), availability of an antiviral agent (such as acyclovir for varicella), immunoglobulins (passive immunity), or an antimicrobial agent.

We conducted a systematic literature review on the safety and effectiveness of the YFV in patients with CIMID, guided by the most frequent questions addressed by healthcare professionals and patients on this issue. Thus, the objective of this study was to develop individualized YFV recommendations for this special group of patients.

\section{Methods}

This was an initiative of the Brazilian Rheumatology Society (BRS); to develop YFV-specific recommendations for this special group of patients, considering the national epidemiological scenario, based on scientific evidence.

\section{Study method}

To develop the recommendations, the BRS followed an internationally validated methodology, according to the GIN-McMaster Guideline Development Checklist (https:// cebgrade.mcmaster.ca/guidelinechecklistonline.html). The Society counted on a work group comprised of clinical practitioners with expertise in different CIMID types, such as the Brazilian Dermatology Society (BDS) and the Brazilian Inflammatory Bowel Diseases Study Group (GEDIIB). In addition, the BRS invited experts on infectious diseases and vaccination (from Tropical Medicine, Infectious Diseases and Immunization National Societies) to take part in the process.

The chair of the group (GSP) was chosen and endorsed by the BRS, who defined groups to run the process of developing recommendations: the oversight committee, composed of five rheumatologists (LM, AMK, SK, MRA, VMFT), specialists in systematic reviews and the Grading of Recommendations Assessment, Development and Evaluation Working Group (GRADE), and a postgraduate student from the Evidence Based Medicine postgraduate program (APR).

The oversight committee was responsible for defining the questions that guided the recommendations via weekly Skype meetings, keeping the guideline development on track, the goals and objectives, timeline, task 
assignments, documenting the decisions, and proposing the methodology for all steps. The committee was also in charge of including and developing search strategies, running searches and selection of evidence, and critically appraising the existing evidence and establishing methods for identifying additional evidence.

The other workgroup, the panel members, was composed of experts representing the above-mentioned societies and two representatives of National groups of patients (PT, ET). These representatives are both very engaged in continuous education and advocacy and have sufficient knowledge on CIMID diseases, regularly giving on-line and presential support to patients around Latin America. They did not receive any incentive to participate in the panel and did not receive any tool to help their decisions during the recommendation development process. They participated in all steps of the process, which were transparent to all members, and their votes had the same weight as all others.

\section{Search strategy}

The systematic literature review was performed in electronic and manual databases, using terms derived from the main question of the study, formulated using PICO format (terms described in Table 1).

\section{Analysis of the methodological quality of the studies}

For this evaluation, the Cochrane Collaboration risk of bias table was used for the intervention studies [36]. For observational studies, we used the Newcastle-Ottawa Quality Assessment Scale [37]. Studies that received scores equal to or greater than six were considered to have good methodological quality.

\section{Quality of evidence}

The quality of the evidence (QoE) reported in this systematic literature review was analyzed based on the GRADE approach [38]. As studies with different levels of evidence were included in the recommendation development, the oversight committee chose to split them into two categories: in comma-separated sequences or in intervals, separated by hyphens [39].

\section{Delphi methodology}

When the quality of the evidence was low or there was a lack of evidence, the opinion of the expert panel was used to support the decisions to determining the recommendations.

To achieve consensus among panel members, Delphi methodology was employed [40]. A face-to-face meeting was arranged and held on November 30, 2017 to present the literature reviewed to the panel and train them on Delphi methodology voting, where all participants should anonymously assign a score from 0 to 100 on a continuous scale to each recommendation, with 0 indicating total disagreement and 100 absolute agreement.

Recommendations were refined and voted on by all work groups (oversight and panel) through a series of three online Delphi rounds supervised by the chair (GSP). From these grades, a final level of agreement (LoA) score was allocated to each recommendation. It was a consensus for all work groups that a recommendation was accepted when it achieved $\geq 80 \%$ agreement among the panel, including the patient representatives.

\section{Sample}

We included all the studies found by the search strategy specified above, with no language restrictions.

\section{Eligibility criteria}

Studies included: clinical trials, observational studies, and case studies on the effectiveness and/or safety of YFV that included CIMID patients with or without treatment.

\section{Intervention}

The YFV was considered as the intervention when compared to placebo.

\section{Outcomes}

For assessing YFV safety, the following aspects were considered:

- AEFV, most severe adverse events (SAE), including YEL-AVD and YEL-AND,

Table 1 Terms used for the literature review search using the PICO Format

\begin{tabular}{ll}
\hline $\begin{array}{l}\text { Population with or without } \\
\text { treatment }\end{array}$ & $\begin{array}{l}\text { Patients with rheumatoid arthritis OR juvenile idiopathic arthritis OR systemic lupus erythematosus OR systemic } \\
\text { sclerosis OR psoriatic arthritis OR spondyloarthritis OR Sjögren's syndrome OR vasculitis OR inflammatory myopathy } \\
\text { OR dermatomyositis OR psoriasis OR Crohn's disease OR ulcerative colitis }\end{array}$ \\
\hline Intervention & yellow fever vaccine \\
Comparison & Placebo OR no intervention \\
Outcomes & $\begin{array}{l}\text { immunization, safety, severe adverse events, viscerotropic disease associated with yellow fever vaccine, immunogenicity, } \\
\text { response, effectiveness, efficacy, seroconversion, disease activity: DAS28, ACR 30/50/70. BASDAl, SLEDAl, HAQ / CHAQ, } \\
\text { VASDAl, CMAS, MMT }\end{array}$
\end{tabular}

Terms used for the search related to treatment: abatacept, acitretin, adalimumab, anti-CD20, anti-IL-1, anti-IL-6, anti-IL17, anti-IL23, anti-JAK, anti-TNF, azathioprine, belimumab, canakinumab, certolizumab, cyclophosphamide, CTLA4 lgG, etanercept, golimumab, hydroxychloroquine, infliximab, leflunomide, methotrexate, methylprednisolone, mycophenolate mofetil, prednisolone, prednisone, rituximab, secukinumab, sulfasalazine, tacrolimus, tocilizumab, tofacitinib, ustequikinumab 
- risk of infection with attenuated vaccine strain,

- relapse or worsening of underlying disease activity.

The response to YFV was evaluated considering the following terms as surrogates for efficacy: immunogenicity, seroconversion, and effectiveness.

\section{Questions defined using PICO format}

Initial questions regarding YFV safety in patients with CIMID, receiving or not immunosuppressive medications, were divided according to vaccine exposure to primary vaccination and revaccination (re-exposure) (see Table 2).

\section{Study selection and data extraction}

Two reviewers independently assessed the titles and abstracts of all studies selected by the search strategy group. The full texts of the eligible studies were then retrieved. Two reviewers selected the studies to be included, and disagreements were resolved either by consensus or by the opinion of a third reviewer. A standard data extraction sheet was developed for this review. For the eligible studies, two reviewers extracted the data independently. The discrepancies were resolved by discussion or, where necessary, by consulting a third reviewer.

\section{Results}

\section{Studies selected and data extracted}

From the entire database search, 175 articles were identified, and nine additional studies were selected from other sources (congress abstracts). Among the 184, only 36 were eligible and 148 were excluded, either for not meeting the inclusion criteria (113) or for being duplicates (35). After evaluating the 36 selected studies, a further 19 were excluded for methodological reasons; they were not observational studies or randomized clinical trials. Finally, 17 studies were selected for qualitative analysis and none for quantitative analysis. The flow chart in Fig. 1 depicts the selection process for Systematic Reviews.

Eleven of the 17 selected studies were observational (cohort, case control, or cross-sectional studies) and 6 were case series. Based on these 11 observational studies, a total of 692 patients were included for the safety analyses. The participants were subjects who had received the YFV despite a diagnosis of CIMID and no SAE was reported. There was no difference in AEFV occurrence between patients and healthy individuals [35, 41-48].

Recently, Valim et al. (2017) carried out an observational study evaluating the safety of selected patients with rheumatic diseases after a primary YF vaccination. The authors enrolled 241 patients with rheumatic diseases for whom no SAE was reported and 40 healthy controls [46]. This is an ongoing study and we had access to only partial results from a conference abstract.
Table 2 Questions used to formulate the recommendations

1. Are there specific restrictions on the indication of YFV in patients with CIMID baseline disease, activity, or medication use facing a yellow fever outbreak?

2. Is the risk of SAE following primary or booster YFV vaccination higher in patients with CIMID? Is this related to disease type or activity?

3. Is the risk of SAE following primary and booster YFV vaccination higher in patients using corticosteroid or CSDMARD, TsDMARD or JAK inhibitors?

4. Is the risk of SAE after primary or booster YFV vaccination higher in patients with CIMID using immunosuppressive drugs (azathioprine, cyclophosphamide, cyclosporine, mycophenolate mofetil/acid) or bDMARD?

5. Should an interval be recommended between YFV application (primary or booster) and initiation or restart of medications for CIMID treatment?

6. Should a minimum interval be recommended between discontinuation of medications for CIMID treatment and YFV application (primary or booster)?

7. Does the concomitant application of other vaccines interfere in the YFV response in patients receiving or not CIMID treatment?

8. Is there any contraindication of YFV in close contacts or people living with CIMID patients?

9. Does the use of immunomodulatory and/or immunosuppressive agents in patients with CIMID interfere in the YFV response or long-term efficacy?

YFV: yellow fever vaccine; CIMID: chronic immune-mediated inflammatory diseases; DMARD: disease modifying anti-rheumatic drugs; csDMARD conventional synthetic DMARD - methotrexate, leflunomide, sulfasalazine and antimalarials (hydroxychloroquine and chloroquine); tsDMARD: synthetic target-specific DMARD - tofacitinib; bDMARD: biological DMARD - tumor necrosis factor inhibitors/TNFi (adalimumab, certolizumab, etanercept, golimumab, infliximab), T-lymphocyte costimulation modulator (abatacept), anti-CD20 (rituximab), and IL-6 receptor blocker (tocilizumab)

All included studies had methodological limitations regarding the design or development and did not describe adequate statistical analysis data to evaluate the magnitude of effect. In addition, we only had access to the partial results of three included studies at the time of our review, as they were conference abstracts from ongoing studies [43, $46,47]$. For this reason, we could not estimate the effect or quality of evidence.

Three studies [21, 42, 48] did not include randomly selected controls and the vaccinated group was not homogeneous, with very different sample sizes in the control group and intervention group. Only one study (Scheinberg 2010) included randomly selected controls and included a homogeneous sample [44].

Scheinberg et al. (2010) carried out a study with 17 patients with RA who received a YFV booster during treatment with methotrexate and infliximab. In 15 patients, serology was analyzed by immunofluorescence before and after vaccination. The results were compared with a control group. The YFV was administered 30 days after the last infusion of anti-TNF. Of 17 patients, only one did not seroconvert. Although there was a trend towards lower antibody titers in the 


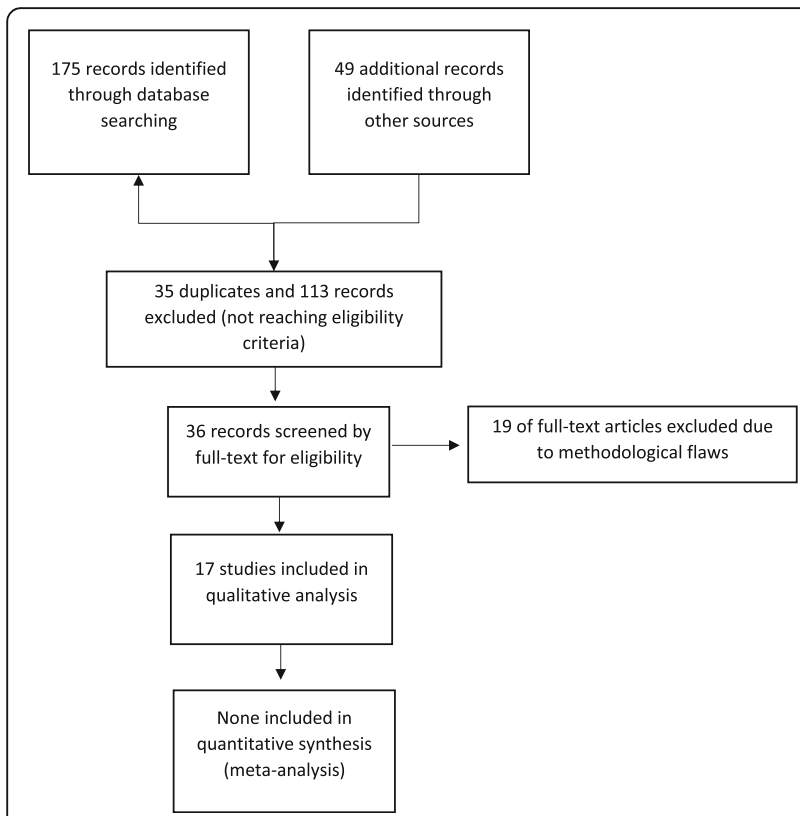

Fig. 1 Flow chart of the studies selection process during the systematic review

RA group, unfortunately, the authors did not apply any statistical tests [44].

Five observational studies $[41,42,44,45,48]$ evaluated the neutralizing antibodies to YFV in 180 patients with CIMID using immunosuppressant drugs, including corticosteroids, synthetic or biological. The authors concluded that all immunocompromised patients were able to develop a protective response to the yellow fever booster. The quality of evidence was very poor.

Oliveira et al. (2015) analyzed the presence of neutralizing antibodies in 31 patients diagnosed with rheumatic diseases who had been inadvertently vaccinated with a booster of YFV (without the physician's knowledge) [45] during a YF outbreak (2007-2008). Twenty-three subjects with RA, five with SLE, two with ES, and one with ankylosing spondylitis were included in the study. The patients were taking various immunomodulatory drugs, such as MTX, leflunomide, infliximab, or rituximab. A plaque reduction neutralization test (PRNT) was performed to evaluate the immunogenicity to the YFV, with values $\geq 794 \mathrm{mIU} / \mathrm{ml}$ considered protective. In total, 27 out of 31 (87\%) presented protective titers of neutralizing antibodies. The lowest PRNT value was in a patient who had used rituximab prior to the booster [45].

Another observational study collected data from patients using corticosteroids who were planning to travel to endemic regions for YF. The control group consisted of healthy individuals matched for age and history of YFV. The safety and immunogenicity of the $17 \mathrm{D}$ vaccine was evaluated. Forty participants in the study group and 77 in the control group were enrolled. The main diseases of the study group were RA and other CIMIDs. The dose of prednisone or equivalent ranged from 5 to $20 \mathrm{mg} /$ day, and $71 \%$ had been using the drug for more than 15 days before the YFV, with an average of ten months of use [48]. There were no serious adverse events; however, the patient group presented a higher frequency of mild reactions, with relative risk $(\mathrm{RR})=8.0$ and a $95 \%$ confidence interval $(\mathrm{CI})$ : 1.4-45.9. In this study, the neutralizing antibodies were also measured by PRNT. All participants had titers $\geq 1: 10$. There were no differences between the groups that received primary or booster YFV [48]. It is important to mention they specifically evaluated patients vaccinated while using corticosteroids. However, the dosage was low, not reaching immunosuppressive doses. Furthermore, as the study was not blind, bias may have occurred [48].

Recently, Wieten et al. (2016) studied 15 immunocompromised patients who were vaccinated inadvertently or after a risk-benefit analysis had been performed by the attending physician. Neutralizing antibodies were measured by PRNT, and an analysis of PBMC (peripheral blood mononuclear cells) and $T$ cells as well as analysis of the cytokine profile produced by CD8+ lymphocytes specific for the yellow fever virus were performed. The results were compared to a control group composed of 41 healthy individuals who were matched for age, sex, and time of vaccination $[41,42]$.

The neutralizing antibody dosage was similar between groups, with $100 \%$ of the immunocompromised individuals and $96.7 \%$ of the control group presenting protective levels. Specific CD8+ cells, were also comparable in relation to the frequency, with a gradual decline over the years after vaccination. Other results showed that there were no significant differences in the phenotypic and cytotoxic profile of specific $\mathrm{T}$ cells. The production of cytokines was also equivalent between the groups [41, 42].

This was the first study to analyze the profile of the immunological alterations post the YFV in immunocompromised individuals, although the sample was small and became even smaller when the authors performed the analysis of subgroups.

In another study, Wieten et al. (2016) analyzed blood samples from 15 immunocompromised patients and 12 healthy controls in order to compare PRNT and serology values by immunofluorescence. Of the patients evaluated, 11 were on methotrexate, two on etanercept, one on prednisone, and one on leflunomide. The medication was withdrawn around two to six weeks in three patients. Using the PRNT method, $100 \%$ of the study group demonstrated protective levels of neutralizing antibodies compared to $83.3 \%$ of 
the control group. Regarding immunofluorescence serology, only $47 \%$ of the study group was seropositive, and no sample was positive in the control group. There was no correlation between PRNT and immunofluorescence $[21,41,42]$.

A recent Brazilian study by Ferreira et al. (2017), performed a long-term follow-up including 144 RA patients treated with immunomodulatory and immunosuppressive specific drugs who were inadvertently vaccinated. The authors evaluated the humoral and cellular immunity profile to YFV and demonstrated a reduced frequency of memory lymphocytes among previously vaccinated patients when compared to healthy controls. Based on this data, the authors concluded that patients taking synthetic or biological drugs were unprotected by the 17DD YFV after a five-year follow-up [43]. This is an ongoing study and we had access to only partial results from a conference abstract.

There are some case reports in the literature to support these results, such as a 63-year-old woman diagnosed with Crohn's disease who received the 17D vaccine during the use of adalimumab. The vaccine was given four days before the next dose, which is usually administered every 14 days. Blood samples were collected on days 12, 18, and 26 post-immunization for viral RNA analysis and detection of neutralizing antibodies. There were no adverse effects. No viremia was detected on day 12, and from day 18 onward, protective levels of neutralizing antibodies were recorded. In this case, it is important to point out that it was the primary dose [49].

All the studies were judged as very low quality of evidence due to methodological limitations, including small sample sizes and lack of statistical data to evaluate the magnitude of the effect. Another limitation identified was a wide range of follow-up and analyses applied in the studies, varying from six days to eight years.

Additionally, given the lack of consensus on defining immunosuppression degrees among national and international Societies and evidence to support this strategy, the Brazilian societies involved in the treatment of patients with CIMID assembled to discuss and vote on it, aiming to standardize these definitions and enable establishment of recommendations. A panel of 22 specialists, representing several committees of the BRS, in addition to two representatives of the Brazilian Society of Dermatology (BDS), the Brazilian Infectious Diseases Society (BIDS), and the study group on Inflammatory Bowel Diseases (GEDIIB), conducted a careful literature review. This step was followed by anonymous voting to categorize the immunosuppression degree of patients with CIMID. For this classification, more than $80 \%$ agreement was required among the members for each item, applied to develop the recommendations for vaccine indication or contraindication.
Complete information on this part of the guidelines process will be published in a separate paper by the same work group (Manuscript in preparation).

Table 3 summarizes the position of the BRS and the immunosuppression degree conferred by the drugs used to treat patients with CIMID, considering the class of medication and mechanism of action.

As a result, eight recommendations were developed regarding the safety of YFV in patients with CIMID and the immunosuppression degree conferred by the treatment used.

Since there was no consistent evidence to support any kind of conclusion or position for the last question formulated as part of the primary objective, on the immunogenicity to YFV in patients with CIMID, the unanimous decision of the panel of members was that it was not possible to establish recommendations on the effectiveness, in the short and long-term, of YFV in these patients; therefore, the results on this issue will only be described.

\section{Recommendations}

1. YFV should not be administered to patients with CIMID under high immunosuppression. For patients with a low degree or no immunosuppression, it is recommended that the risk of the vaccine be assessed individually. This evaluation should be performed by a physician, preferably the specialist assisting the patient (QoE: very low, LoA: > 90\% of agreement).

2. YFV should not be administered to patients with CIMID with high activity of the underlying disease. However, in clinically stable patients or those with no activity of the underlying disease there is no contraindication to vaccination. The risk to vaccinate in these situations should be assessed individually by a physician, preferably the specialist assisting the patient (QoE: very low, LoA: > 90\% of agreement)

3. YFV should not be administered to patients with CIMID using a high dose of corticosteroid. The risk of vaccinating patients receiving low doses should be assessed individually by a physician, preferably the specialist assisting the patient (QoE: very low, LoA: $>90 \%$ of agreement).

We emphasize an individual-based evaluation, ideally shared decision making (SDM) [50], considering the risks and benefits of vaccination, especially in a high-risk epidemiological setting, because of the severity and mortality rate related to YF infection, as 
Table 3 Immunosuppression degree conferred by drugs used to treat patients with chronic immune-mediated inflammatory diseases: Positioning of the Brazilian Societies of Rheumatology, Dermatology and Study Groups on Inflammatory Bowel

Diseases

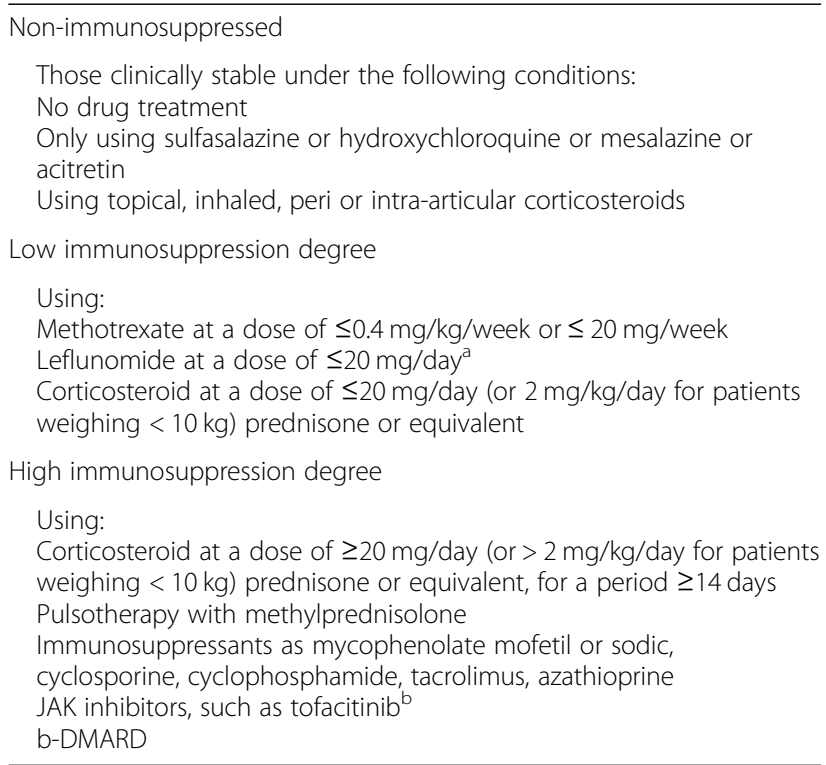

bDMARD: biologic disease modifying anti-rheumatic drugs; As the dosage of serum level of leflunomide is difficult and the studies on the risk of vaccinating individuals taking leflunomide at the usual doses are lacked, in cases requiring vaccination, a drug elimination regimen of $8 \mathrm{~g}$ of cholestyramine 3 times/day for 11 days or $50 \mathrm{~g}$ of activated charcoal 4 times/day for 11 days must be prescribed (similar to Sanofi Pasteur Laboratory recommendation when a woman taking leflunomide become pregnant). If the leflunomide plasma level determination is available it is recommended to reach nondetectable levels (i.e., below $0.02 \mathrm{mg} / \mathrm{l}$ ) before vaccination

well as the possible adverse events of the YFV in an immunosuppression context $[8,13]$.

The Center for Diseases Control and Prevention (CDC) used the GRADE system to evaluate the evidence of SAE following YFV and 1255 cases with a report of SAE following YFV were identified. For the majority $(84 \%)$ of subjects, it was unknown if the SAE occurred following a primary or booster dose of the vaccine. Furthermore, it was not known how many of the 437 million doses of YFV were administered as a primary or booster dose. Of the 201 subjects for whom SAE was reported, the dose type was known, whereas 14 (7\%) occurred following a booster dose of vaccine $[13,19,51-55]$.

In this systematic review, YEL-AVD was reported for 72 subjects; in 41 (57\%) it was unknown if the event occurred following a primary or booster dose of the vaccine. Of the 31 subjects for whom the dose type was known, one (3\%) subject had YEL-AVD after receiving a booster dose of the vaccine; no laboratory testing was performed for that case $[10,11,14,15,34,52,56-60]$. In the same review, YFV-AND was reported for 218 subjects. For 108 (50\%) subjects it was not known whether YEL-AVD occurred following a primary or booster dose of the vaccine. Of the 110 subjects for whom the dose type was known, three (3\%) subjects reported YFV-AND after receiving a booster dose of the vaccine. All three cases were reported as an autoimmune-mediated event rather than direct vaccine viral invasion of the central nervous system and no specific laboratory testing was available to assess vaccine causality $[10,17,52,56-59,61,62]$.

\section{SAE in altered immune status patients}

It is well established that YFV is contraindicated in people with a thymus disorder associated with abnormal immune cell function, such as thymoma or myasthenia gravis. YFV is contraindicated in people with AIDS or other clinical HIV manifestations, including patients with CD4+ T lymphocyte values $<200 / \mathrm{mm}^{3}$ or $<15 \%$ of total lymphocytes for children aged $<6$ years. This recommendation is based on the potential increased risk of encephalitis in this population. It is also contraindicated in patients with primary immunodeficiencies, as well as those with malignant neoplasms or transplants.

There are no data regarding possible increased adverse events or decreased vaccine effectiveness after YFV administration to patients with other chronic medical conditions (such as renal disease, hepatitis $\mathrm{C}$ virus infection, diabetes mellitus, and CIMID). Factors to be considered when assessing a patient's general level of immune competence include disease severity and activity, complications, comorbidities, and current treatment programs, mainly immunosuppressants. As there are no specific data on the use of YFV in these populations to date, the use of LAV is contraindicated according to the majority of package inserts in these therapies.

According to CDC, there are no data available on disease activity and medication used in nine patients diagnosed or potentially diagnosed with autoimmune diseases who developed YEL-AVD by the year 2016 and could potentially be under treatment with immunosuppressive agents. Four out of nine patients were older than 60 years, and two had a previous history of thymectomy - both situations are considered a risk factor for YEL-AVD [11]. According to the CDC and Advisory Committee on Immunization Practices (ACIP) recommendations, there are no contraindications or precautions for this special group of patients regarding underlying diseases. However, the contraindications should be carefully observed, and consideration given to the precautions for vaccination when patients are receiving immunosuppressive therapy, following the recommendations for immunosuppressed individuals $[12,13,19]$. 
Nevertheless, there are some studies performed in Brazil that have shown no SAE related to YFV. The first, published by Mota et al. (2009), reported retrospective data from 70 patients with various rheumatic diseases such as RA, SLE, Spo, and systemic sclerosis (SyS) who were inadvertently vaccinated with YFV. All participants were receiving immunosuppressive therapy. Among them, 22.8\% reported mild adverse events such as rash, headache, and myalgia. There were no serious adverse events, hospitalizations, or deaths due to immunization [35].

Recently, Valim et al. (2017), enrolled 241 patients with rheumatic diseases for whom no SAE was reported, $s$ described above [46]. Additionally, case reports of patients with CIMID using synthetic or biological DMARDs were described without any reported of SAE [33, 35, 41, 42, 44, 45, 49, 63-67].

Since there are scarce data on LAV, such as YFV, in patients with CIMID, guidelines on vaccination for this group are less evidence-based than other immunosuppressive conditions. In addition, it is almost impossible to establish a real causal correlation between an AEFV related to YFV and a CIMID, as this group of diseases encompasses a range of clinical presentation conditions and multivariate manifestations, as well as they have particular differences considering the type of treatment, in general inducing immunosuppressive drugs. These all variables together inducing a wide variation in the immunosuppression degree, which could be further related to susceptibility to infections and can be considered a cause of SAE per se.

Therefore, this section provides recommendations based on the best data available and the practices of experienced clinicians. A special comment about the fractional YFV dose campaign should be highlighted, as, besides the balance between risk/benefits, it is also necessary to consider the shortage of the vaccine. In this situation, if there is an endorsement by national health authorities, our advice is to follow the same recommendations regarding the vaccination safety in patients with CIMID.

\section{Revaccination with YFV should not be administered to patients with CIMID under high immunosuppression. In specific situations in which a booster is necessary, the risk of vaccinating patients with a low or no immunosuppression degree should be assessed individually by a physician, preferably the specialist assisting the patient (QoE: Very low, LOA: > $90 \%$ of agreement)}

Although booster doses of YFV are not recommended in current epidemiological settings in Brazil, this is a matter of debate. For ACIP and CDC, a booster is recommended for special groups, such as those with HIV, post-transplant patients, and may be considered for travelers who received their previous dose of YFV $\geq 10$ years ago and plan to remain for a prolonged period in endemic or ongoing outbreak areas $[13,19]$.

\section{In situations of risk, when YFV is indicated, a minimum interval of four weeks is recommended between application of the vaccine and the initiation or resumption of treatment with immunomodulatory and immunosuppressive drugs (QoE: very low, LOA: > 90\% of agreement).}

6. In situations of risk, when YFV is indicated, a minimum period after the suspension of medications prior to the application of the vaccine is recommended, varying according to the immunosuppression degree. Advice on treatment discontinuation should be individualized and given by a specialist (QoE: very low, LOA: > 90\% of agreement).

There is no strong and consistent evidence to be used as the foundation for establishing recommendations about whether patients with CIMID should be undergoing therapy or not when receiving LAV. The majority of healthcare work in this field follows guidelines based on the experience of other specialists, who manage immunosuppressive therapy in their clinical practice more frequently (e.g. oncologists).

Papadopoulou and Sipsas (2014) performed a search for all the guidelines available on the vaccination of adult patients with CIMID. The authors identified specific protocols in 21 national rheumatology societies, all of them built on an expert opinion panel. Points of agreement include avoiding the use of LAV in immunosuppressed patients. However, the most important differences were based on the immunosuppression degree of patients under different treatments, such as the steroid dose that induces immunosuppression, the time interval between LAV, and the initiation of immunosuppressive treatment. The authors concluded that these significant differences among national recommendations on immunizations in patients with CIMID reflected the lack of evidence-based data [32].

A defined safety period between the onset or withdrawal from immunosuppressive therapy and a vaccination with LAV in patients with CIMID has not been studied; subsequently, the majority of the guidelines are based on expert opinion. There is consensus between the guidelines among the international societies regarding the period recommended between LAV and therapy onset, which is at least one month [30, 31, 33, 68]. However, there is no consensus among these experts on how long the temporary 
discontinuation of immunosuppressive medication should be before vaccination with LAV.

Thus, considering the epidemiological scenario in Brazil and the need for a specific recommendation on YFV for this population, we were motivated to defend our position that the immunosuppression degree induced by the treatment should be the basis for an individualized and safer approach to the vaccination of patients with CIMID. Complete information regarding this study can be found in another publication from this group (Manuscript in preparation). The recommended period that clinicians should wait, after discontinuation of therapy, to administer a live vaccine, is shown in Table 4.

\section{When YFV is indicated to patients with CIMID, it is} recommended that it not be applied concurrently with another live attenuated virus vaccine, primarily with MMR (measles, mumps, and rubella). When indicated, a 28-day interval between the application of these vaccines is recommended (QoE: Very low, LOA: > 90\% agreement)

There is no evidence that inactivated vaccines interfere in the immune response to the yellow fever vaccine. Therefore, inactivated vaccines can be administered either simultaneously or at any time before or after the yellow fever vaccination. The ACIP recommends that the YFV should be administered either simultaneously or 30 days apart from other live viral vaccines as the immune response to one live virus vaccine might be impaired if administered within 30 days of another LAV $[2,69]$. One study involving the simultaneous administration of YFV and MMR vaccines in children found a decrease in the immune response to yellow fever, mumps, and rubella when the vaccines were given on the same day versus 30 days apart. Additional studies are needed to confirm these findings, but they suggest that, if possible, the yellow fever and MMR vaccines should be administered 30 days apart.
8. There is no contraindication of YFVin those inclose contact with immunocompromised patients, since the transmission of the vaccine virus without vector participation is documented only through breast milk, blood donation, and, possibly, by accidental contact with biological materials (QoE: Very low, LOA: > 90\% of agreement)

Healthy and immunocompetent subjects living with immunocompromised patients can and should receive LAV as well as inactivated vaccines, such as MMR, the rotavirus vaccine, varicella, and shingles. In addition, these subjects can safely receive vaccines recommended for travelers, such as typhoid fever and yellow fever [70].

According to the $\mathrm{CDC}$, there is no evidence that people receiving YFV can eliminate the vaccine virus through any specimens [19]. Although detected in the urine of vaccinated individuals, the presence of the yellow fever vaccine virus has never been related to this route of transmission [71].

There is a theoretical risk of YFV being transmitted through blood products, but patients should be allowed to donate two to four weeks after vaccination [72, 73]. In April 2009, the transmission of the yellow fever vaccine virus through breast milk was documented in Brazil for the first time [73, 74].

\section{Discussion}

The development of tailored recommendations for indicating YFV to patients with CIMID, receiving immunosuppressive therapy or not, was a pragmatic project in the field of rheumatology and related specialties. Given the paucity of scientific literature on vaccination for this particular group of patients, the most suitable approach to be adopted was to gather specialists from different areas, together with patients, in an attempt to define the recommendations in a setting with a high YF burden, in light of the knowledge that recommendations in the literature in different settings may not be the most appropriate for this specific group.

Table 4 Minimal period recommended between therapy withdrawal and yellow fever vaccination in patients with CIMID

\begin{tabular}{|c|c|}
\hline Drug & Interval between withdrawal and YFV \\
\hline Prednisone $>20 \mathrm{mg} /$ day or pulse methylprednisolone & At least one month \\
\hline 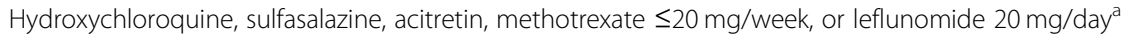 & Consider vaccination without interval \\
\hline Methotrexate > 20 mg/week & At least 1 month \\
\hline Azathioprine, mycophenolate mofetil or sodic, cyclosporine, tacrolimus, or cyclophosphamide & At least 3 months \\
\hline Tofacitinib & At least 2 weeks \\
\hline Anti-cytokines and co-stimulation inhibitor & 4-5 half-lives ${ }^{b}$ \\
\hline B-lymphocyte depletors & $6-12$ months \\
\hline
\end{tabular}

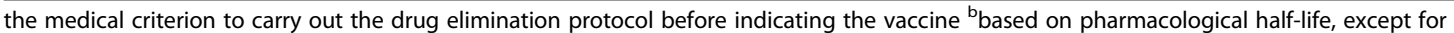
B-lymphocyte depletors 


\section{Strengths}

To our knowledge, this is the first paper to address specific questions, using a Guidelines Grade approach, involving specialists from many areas and patients, on the management of YFV in patients with CIMID living or traveling to YF endemic areas. This paper approaches a real need, assessed by clinicians and patient care groups and might have global applicability, contributing to and supporting vaccination practices.

Additionally, the participation of patients is inedited in the decision process as a motivation to shared decision-making (SDM). It has been argued that SDM represents the pinnacle of patient-centered care; well-informed preference-based patient decisions might lead to safer, more cost-effective healthcare, which in turn might result in improved health outcomes. In practice, these SDMs are seen to occur to a limited extent. In this process, although a patient may not want to make any final decision, they should still be involved in the development of important but difficult recommendations, such as eliciting their concerns and views. Knowledge and awareness among both professionals and patients, as well as tools and skills training, are needed for SDM to become widely implemented [75].

\section{Limitations}

Due to the lack of evidence in the literature to help the development of these recommendations, they were mainly based on expert opinion and panel making decisions. Further research and advances will lead to future revisions and updates.

Thus, in particular here, we consider essential a SDM approach on taking the YFV or not, since these recommendations were based on few evidences and mostly in expert opinion.

\section{Conclusions}

The number of patients with CIMID is increasing as well as those exposed to therapy with a varied range of immunosuppressive degrees. In Brazil, we are facing an alarming epidemic scenario of YF, which is reaching the most populous areas in the country in unvaccinated people.

The majority of vaccination guidelines for this special population do not define recommendations or measures to plan the YFV for this particular group. Thus, given the urgent need for specific recommendations on YFV for this population and the lack of available evidence in the literature, the Brazilian Society of Rheumatology gathered a panel of experts, including representatives from five other related Societies, together with patients, to build these recommendations, prioritizing the vaccination safety and motivation for SDM. These are summarized in Table 5.
Last but not least, our work group would like to address a particular concern of great importance that should be given to the vaccine effectiveness. Due to the lack of evidence regarding short or long-term responses to the primary vaccination, we were not able to draw any recommendations or even advice in this field. However, we consider it fundamental to inform patients with CIMID, who have been inadvertently vaccinated under immunosuppression, that they may not have developed a proper response to the vaccine, so they are advised to take care when exposed to YF high-risk areas, until protection is confirmed by a post vaccination test (PRNT).

Finally, we hope this document will encourage all health professionals involved in the care of this special group of patients, to incorporate vaccination planning into their clinical practice, considering both safety and satisfactory immunogenicity.

Table 5 List of recommendations for yellow fever vaccine (YFV) administration in patients with CIMID

1. YFV should not be administered to patients with CIMID under high immunosuppression. For patients with a low degree or no immunosuppression, it is recommended to assess individually the risk of the vaccine. This evaluation should be performed by a physician, preferably the specialist assisting the patient

2. YFV should not be administered to patients with CIMID with high activity of the underlying disease. However, in clinically stable patients or those with no activity of the underlying disease there is no contraindication to vaccination. The risk to vaccinate in these situations should be assessed individually by a physician, preferably the specialist assisting the patient

3. YFV should not be administered to patients with CIMID using a high dose of corticosteroid. The risk of vaccinating patients receiving low doses should be assessed individually by a physician, preferably the specialist assisting the patient

4. Revaccination with YFV is not recommended for patients with CIMID under high immunosuppression. In specific situations in which a booster is necessary, the risk of vaccinating patients with a low or no immunosuppression degree should be assessed individually by a physician, preferably the specialist assisting the patient

5. In situations of risk, when YFV is indicated, a minimum interval of four weeks is recommended between application of the vaccine and the initiation or resumption of treatment with immunomodulatory and immunosuppressive drugs

6. In situations of risk, when YFV is indicated, a minimum period after the suspension of medications prior to the application of the vaccine is recommended, varying according to the immunosuppression degree. Advice on treatment discontinuation should be individualized and given by a specialist

7. When YFV is indicated in patients with CIMID, it is recommended that it not be applied concurrently with another live attenuated virus vaccine, primarily with the MMR (measles, mumps, and rubella). When indicated, a 28-day interval between the application of these vaccines is recommended

8. There is no contraindication of YFV in those in close contact with immunocompromised patients, since the transmission of the vaccine virus without vector participation is documented only through breast milk, blood donation, and, possibly, by accidental contact with biological materials 


\section{Abbreviations}

ACIP: Advisory Committee on Immunization Practices; ACR: American College of Rheumatology; AEFV: Adverse Event Following Vaccination; AIDS: Acquired Immunodeficiency Syndrome; AS: Ankylosing Spondylitis; BDM: Brazilian Dermatology Society; bDMARD: Biological Disease-Modifying Drugs; BIDS: Brazilian Infectious Diseases Society; BRS: Brazilian Rheumatology Society; CDC: Centers for Diseases Control and Prevention; CIMID: Chronic Immune-Mediated Inflammatory Diseases; csDMARD: Conventional Synthetic Disease-Modifying Drugs; DMARD: Disease Modifying Anti-Rheumatic Drugs; EULAR: European League Against Rheumatism; GEDIIB: Inflammatory Bowel Diseases Study Group; GRADE: Grading of Recommendations Assessment, Development and Evaluation Working Group; HIV: Human Immunodeficiency Virus; IBD: Inflammatory Bowel Diseases; IFA: Indirect Immunofluorescence Test; IFIT: Tetracyclic Peptide Repeats; IL: Interleukin; IRF: Interferon Regulator Factor; LAV: Live Attenuated Vaccines; LoA: Level of Agreement; MMR: Measles-Mumps-Rubella; MS: Multiple Sclerosis; PBMC: Peripheral Blood Mononuclear Cells; PCR: C-reactive protein; PRNT: Plaque Reduction Neutralization Test; PsoA: Psoriatic Arthritis; QoE: Quality of the Evidence; RA : Rheumatoid Arthritis; RNA : Ribonucleic Acid; RR: Relative Risk; SAE: Serious Adverse Event; SDM: Shared decision-making; SLE: Systemic Lupus Erythematosus; SPF : Specific Pathogen Free; Spo: Spondyloarthropathies; STAT: Transcription Activator; SyS: Systemic Sclerosis; TLR: Toll-like receptor; TNF: Tumor Necrosis Factor; TNFi: Tumor Necrosis Factor Inhibitors; tsDMARD: Synthetic Target-Specific Disease-Modifying Drugs; WHO: World Health Organization; YEL-AND: Yellow Fever Vaccine-Associated Neurotropic Disease; YEL-AVD: Yellow Fever Vaccine-Associated Viscerotropic Disease; YF: Yellow Fever; YFV: Yellow Fever Vaccine

\section{Acknowledgements}

The authors would like to thank Priscila Torres and Eduardo Tenorio, both patients from the supporting groups Encontrar/Grupar and Superando o Lupus for participating in the panel and attending the meeting. Furthermore, we would like to give special thanks to Dr. Jose Tupinanbá Sousa Vasconcelos, scientific director of SBR, for the fundamental support to this work.

\section{Funding}

Brazilian Society of Rheumatology. The funding participants had no role in the design of the study, collection, analysis, and interpretation of data, or in writing the manuscript.

\section{Availability of data and materials}

The data that support the findings of this study are available from [third party name] but restrictions apply to the availability of these data, which were used under license for the current study, and so are not publicly available. Data are however available from the authors upon reasonable request and with permission of [third party name]. The data have been used in another manuscript in preparation, after which all information will be shared.

\section{Authors' contributions}

The oversight committee was involved in searching the literature and selecting studies. All the authors contributed to analyzing the studies, and drafting or critically revising the manuscript for important intellectual content. All of them gave their final approval of the version to be published and have sufficiently participated in the study to take public responsibility for the content; and agree to be accountable for all aspects of the study in ensuring that questions related to the accuracy or integrity of any part of the study are appropriately investigated and resolved.

\section{Ethics approval and consent to participate}

Not applicable.

\section{Consent for publication}

Approved by all authors, the corresponding author assumes responsibility.

\section{Competing interests}

Adriana Maria Kakehasi Research funds: CNPq, SBR, FAPEMIG Support for Scientific Events: Abbvie, BMS, Janssen Lecture Fees: UCB, Janssen, Pfizer, Roche, BMS Clinical research: Roche, Pfizer Advisory board: Janssen, Roche, BMS, Pfizer.

Alexandre Wagner $\mathbf{S}$ de Souza has received financial support as an advisory board member for Roche. Financial competing interest: none.
Caroline Araújo Magnata da Fonte: none.

Clayton Brenol Has received personal or institutional support from Abbvie, Bristol, Janssen, Pfizer and Roche; has delivered speeches at events related to this work and sponsored by Abbvie, Pfizer and Roche. Financial competing interest: none.

Claudia Marques: Non-financial and financial competing interests related to this publication

Cyrla Zaltman: Non-financial and financial competing interests related to this publication

Eduardo Ferreira Borba was supported by grants from Conselho Nacional de Desenvolvimento Científico e Tecnológico (CNPq \#307226/2014-0). Financial competing interest: none.

Gecilmara Salviato Pileggi has received fees for lectures and talks at events related to this study sponsored by Abbvie, Janssen, and UCB. The authors declare no financial competing interest.

Georges Basile Christopoulos: none

leda M M Laurindo - has no competing interests related to this work. Financial competing interests: none. Isabella Ballalai: has received funding for meetings related to this work sponsored by the Brazilian Ministry of Health (CTAI-PNI), fees for lectures and advisory board sponsored by Sanofi Pasteur, Pfizer and MSD. Izaias Pereira da Costa Non-financial competing interests Lessandra Michelin has received funding for meetings related to this work sponsored by the Brazilian Ministry of Health (CTAI-PNI). Financial competing interest: none.

Licia Maria Henrique da Mota Has received personal or institutional support from Abbvie, Janssen, Pfizer and Roche; has delivered speeches at events related to this work and sponsored by Abbvie, Janssen, Pfizer, Roche and UCB. Financial competing interest: none.

Lilian David de Azevêdo Valadares has received for lectures fees and speeches at events related to this work sponsored by Janssen and Novartis. Financial competing interest: none.

Liliana Andrade Chebli has received for lecture fees and speeches at events not related to this work sponsored by Takeda. Financial competing interest: none.

Marcos Renato de Assis has received personal or institutional support from Apsen and Lilly; has given lectures and/or consultancy to Novartis, UCB and Janssen not related to this work. Financial competing interest: none. Marcus Vinícius Guimarães de Lacerda has no conflict of interest. Michel Alexandre Yazbek has no competing interests related to this work. Financial competing interests: none.

Rejane Maria Rodrigues de Abreu Vieira has no conflicts of interest. Renato Kfouri has received fees for lectures and advisory board sponsored by Sanofi Pasteur.

Rosana Richtmann has received for lectures fees sponsored by Abbvie, Pfizer and MSD. Financial competing interest: none.

Selma Merenlender is presently supported by SRRJ.

Valéria Valim has no competing interest.

\section{Publisher's Note}

Springer Nature remains neutral with regard to jurisdictional claims in published maps and institutional affiliations.

\section{Author details}

${ }^{1}$ SBR. Faculdade de Ciências da Saúde de Barretos - FACISB, Barretos, São Paulo, Brazil. ${ }^{2}$ SBR. Serviço de Reumatologia do Hospital Universitário de Brasília, Universidade de Brasília, Brasília, Brazil. ${ }^{3}$ SBR. Faculdade de Medicina, Universidade Federal de Minas Gerais, Belo Horizonte, Brazil. ${ }^{4}$ SBR. Escola Paulista de Medicina, Universidade Federal de São Paulo, São Paulo, Brazil. ${ }^{5}$ Pós graduanda do programa de Medicina Baseada em Evidências, Universidade Federal do Estado de São Paulo (UNIFESP), São Paulo, Brazil. ${ }^{6}$ SBR. Hospital Universitário Lauro Wanderley, Universidade Federal da Paraíba (UFPB), João Pessoa, Brazil. ' $5 B R$. Hospital Getulio Vargas, Recife, Brazil. ${ }^{8}$ SBD. Faculdade de Medicina do ABC, Santo Andre, Brazil. ${ }^{9}$ SBR. Hospital de Clínicas de Porto Alegre, Universidade Federal do Rio Grande do Sul, Porto Alegre, Brazil. ${ }^{10}$ SBR. Hospital das Clínicas, Universidade Federal de Pernambuco, Recife, Brazil. ${ }^{11}$ GEDIIB. Presidente do GEDIIB 2017-2019, Universidade Federal do Rio de Janeiro, Rio de Janeiro, Brazil. ${ }^{12}$ SBR. Hospital das Clinicas, Faculdade de Medicina, Universidade de Sao Paulo, Sao Paulo, Brazil. ${ }^{13}$ SBR. Diretor médico do Centro de infusão do Hospital Humanitas, Varginha, Brazil. ${ }^{14} \mathrm{SBR}$. Unidade Docente Assistencial de Reumatologia, 
Universidade do Estado do Rio de Janeiro, Rio de Janeiro, Brazil. ${ }^{15}$ SBR. Presidente da Sociedade Brasileira de Reumatologia, Maceio-AL, Brazil. ${ }^{16} \mathrm{SBR}$. Escola de Medicina da Universidade Nove de Julho, São Paulo, Brazil. ${ }^{17} \mathrm{SBIm}$. Vice-Presidente da Sociedade Brasileira de Imunizações (SBIm), SBiM, Rio de Janeiro, Brazil. ${ }^{18}$ SBR. Professor da Faculdade de Medicina da Universidade Federal do Mato Grosso do Sul, Cuiabá, Brazil. ${ }^{19}$ SBI. Professora na faculdade de Medicina, Universidade de Caxias do Sul, Caxias do Sul, Brazil. ${ }^{20}$ SBR. Reumatologista. Hospital Getulio Vargas, Recife, Brazil. ${ }^{21}$ GEDIIB, Faculdade de Medicina da Universidade Federal de Juiz de Fora, Juiz de Fora, Brazil.

${ }^{22}$ SMBT. Instituto Leônidas e Maria Deane (Fiocruz - Amazônia), Fundação de Medicina Tropical Dr. Heitor Vieira Dourado (FMT-HVD), Maceio-AL, Brazil.

${ }^{23}$ SBR. Medica reguladora da Secretaria Estadual da Saúde de Santa Catarina, Florianópolis, Brazil. ${ }^{24}$ SBR. Escola de Medicina, Universidade Estadual de Campinas, Campinas, Brazil. ${ }^{25}$ SBR. Hospital Geral de Fortaleza e Universidade de Fortaleza, Fortaleza, Brazil. ${ }^{26} \mathrm{SBD}$. Faculdade de Medicina da Universidade Estadual de Campinas, Campinas, Brazil. ${ }^{27}$ SBIm. Presidente do Departamento de Imunizações da Sociedade Brasileira de Pediatria (SBP), Maceio-AL, Brazil. ${ }^{28} \mathrm{SBI}$. Instituto de Infectologia Emilio Ribas, Maceio-AL, Brazil. ${ }^{29} \mathrm{SBR}$. Presidente da SRRJ. Chefe do Serviço de Reumatologia do Hospital Estadual Eduardo Rabelo RJ, Rio de Janeiro, Brazil. ${ }^{30}$ SBR. Faculdade de Medicina, Universidade Federal do Espírito Santo, Vitória, Brazil. ${ }^{31}$ SBR. Escola Médica de Marilia, Marilia, Brazil. ${ }^{32}$ SBR. Universidade federal do Paraná, Curitiba, Brazil. ${ }^{33}$ SBR. Universidade Federal de São Paulo (UNIFESP), São Paulo; Universidade Santo Amaro (UNISA), Sao Paulo, Brazil. ${ }^{34}$ School of Medical Science BarretosFACISB, Avenue Masonic Lodge Renovadora 68, No. 100 - Airport Neighborhood, Barretos/SP 14785-002, Brazil.

\section{Received: 17 July 2018 Accepted: 6 March 2019}

Published online: 29 April 2019

\section{References}

1. Monath TP. Yellow fever: an update. Lancet Infect Dis. 2001;1:11-20.

2. Staples JE, Gershman M, Fischer M, Centers for Disease C, Prevention. Yellow fever vaccine: recommendations of the advisory committee on immunization practices (ACIP). MMWR Recomm Rep. 2010;59(RR-7):1-27.

3. Brasil: Febre amarela - Guia para Profissionais de Saúde. Ministério da Saúde do Brasil.Brasília; 2018.

4. Febre amarela: Ministério da Saúde atualiza casos no país. In:[http:// portalms.saude.boletim-epidemiologico/noticias/agencia-saude/42940-febreamarela-ministerio-da-saude-atualiza-casos-no-pais-6]. Acess in 24/nov/2018.

5. Verma R, Khanna P, Chawla S. Yellow fever vaccine: an effective vaccine for travelers. Hum Vaccin Immunother. 2014;10(1):126-8.

6. Campi-Azevedo AC, Costa-Pereira C, Antonelli LR, Fonseca CT, TeixeiraCarvalho A, et al. Booster dose after 10 years is recommended following 17DD-YF primary vaccination. Hum Vaccin Immunother. 2016; 12(2):491-502.

7. Cavalcante KR, Tauil PL. Epidemiological characteristics of yellow fever in Brazil, 2000-2012. Epidemiol Serv Saude. 2016;25(1):11-20.

8. Lindsey NP, Schroeder BA, Miller ER, Braun MM, Hinckley AF, Marano N, et al. Adverse event reports following yellow fever vaccination. Vaccine. 2008; 26(48):6077-82.

9. WHO. Immunization Safety Surveillance: Guidelines for Immunization Programme Managers on Surveillance of Adverse Events Following Immunization Regional Office for the Western Pacific Region. World Health Organization. Manila: WHO Press; 2013.

10. Breugelmans JG, Lewis RF, Agbenu E, Veit O, Jackson D, Domingo C, et al. Adverse events following yellow fever preventive vaccination campaigns in eight African countries from 2007 to 2010. Vaccine. 2013;31(14):1819-29.

11. Whittembury A, Ramirez G, Hernandez H, Ropero AM, Waterman S, Ticona $M$, et al. Viscerotropic disease following yellow fever vaccination in Peru. Vaccine. 2009;27(43):5974-81.

12. Ferreira CC, Campi-Azevedo AC, Peruhype-Magalhaes V, Costa-Pereira C, Albuquerque CP, Muniz LF, Yokoy de Souza T, et al. The 17D-204 and 17DD yellow fever vaccines: an overview of major similarities and subtle differences. Expert Rev Vaccines. 2018;17(1):79-90.

13. Chiodini J. The CDC yellow book app 2018. Travel Med Infect Dis. 2017.

14. Gershman MD, Staples JE, Bentsi-Enchill AD, Breugelmans JG, Brito GS, Camacho LA, et al. Viscerotropic disease: case definition and guidelines for collection, analysis, and presentation of immunization safety data. Vaccine. 2012;30(33):5038-58.
15. Thomas RE. Yellow fever vaccine-associated viscerotropic disease: current perspectives. Drug Des Devel Ther. 2016;10:3345-53.

16. Staples JE, Gershman MD. Yellow fever vaccines. In: Plotkin SAOW, Offit PA, Edwards KM, editors. Vaccine. 7th ed. Philadelhia: Elsevier; 2017.

17. Martins R, Pavao AL, de Oliveira PM, dos Santos PR, Carvalho SM, Mohrdieck RF, et al. Adverse events following yellow fever immunization: report and analysis of 67 neurological cases in Brazil. Vaccine. 2014;32(49):6676-82.

18. Gotuzzo E, Yactayo S, Cordova E. Efficacy and duration of immunity after yellow fever vaccination: systematic review on the need for a booster every 10 years. Am J Trop Med Hyg. 2013;89(3):434-44.

19. Staples JE, Bocchini JA, Rubin L Jr, Fischer M. Yellow fever vaccine booster doses: recommendations of the advisory committee on immunization practices, 2015. MMWR Morb Mortal Wkly Rep. 2015; 64(23):647-50.

20. Amanna IJ, Slifka MK. Questions regarding the safety and duration of immunity following live yellow fever vaccination. Expert Rev Vaccines. 2016; 15(12):1519-33.

21. Wieten RW, Jonker EF, van Leeuwen EM, Remmerswaal EB, Ten Berge IJ, de Visser AW, et al. A single 17D yellow fever vaccination provides lifelong immunity; characterization of yellow-fever-specific neutralizing antibody and T-cell responses after vaccination. PLoS One. 2016;11(3):e0149871.

22. Ahuka-Mundeke S, Casey RM, Harris JB, Dixon MG, Nsele PM, Kizito GM, et al. Immunogenicity of fractional-dose vaccine during a yellow fever outbreak - preliminary report. N Engl J Med. 2018.

23. Watson AM, Klimstra WB. T cell-mediated immunity towards yellow fever virus and useful animal models. Viruses. 2017;9(4).

24. Simoes M, Camacho LA, Yamamura AM, Miranda EH, Cajaraville AC, da Silva Freire M. Evaluation of accuracy and reliability of the plaque reduction neutralization test (micro-PRNT) in detection of yellow fever virus antibodies. Biologicals. 2012;40(6):399-404.

25. Mercier-Delarue S, Durier C, Colin de Verdiere N, Poveda JD, Meiffredy $V$, Fernandez Garcia MD, et al. Screening test for neutralizing antibodies against yellow fever virus, based on a flavivirus pseudotype. PLoS One. 2017;12(5):e0177882.

26. Silva ML, Martins MA, Espirito-Santo LR, Campi-Azevedo AC, Silveira-Lemos D, Ribeiro JG, et al. Characterization of main cytokine sources from the innate and adaptive immune responses following primary 17DD yellow fever vaccination in adults. Vaccine. 2011;29(3):583-92.

27. Fuertes Marraco SA, Soneson C, Cagnon L, Gannon PO, Allard M, Abed Maillard $\mathrm{S}$, et al. Long-lasting stem cell-like memory CD8+ T cells with a naive-like profile upon yellow fever vaccination. Sci Transl Med. 2015;7(282):282ra248.

28. Bayry J, Radstake TR. Immune-mediated inflammatory diseases: progress in molecular pathogenesis and therapeutic strategies. Expert Rev Clin Immunol. 2013;9(4):297-9.

29. Youinou P, Pers JO, Gershwin ME, Shoenfeld Y. Geo-epidemiology and autoimmunity. J Autoimmun. 2010;34(3):J163-7.

30. Buhler S, Eperon G, Ribi C, Kyburz D, van Gompel F, Visser LG, et al. Vaccination recommendations for adult patients with autoimmune inflammatory rheumatic diseases. Swiss Med Wkly. 2015;145:w14159.

31. van Assen S, Agmon-Levin N, Elkayam O, Cervera R, Doran MF, Dougados M, et al. EULAR recommendations for vaccination in adult patients with autoimmune inflammatory rheumatic diseases. Ann Rheum Dis. 2011;70(3):414-22.

32. Papadopoulou D, Sipsas NV. Comparison of national clinical practice guidelines and recommendations on vaccination of adult patients with autoimmune rheumatic diseases. Rheumatol Int. 2014;34(2):151-63.

33. Croce $E$, Hatz C, Jonker EF, Visser LG, Jaeger VK, Buhler S. Safety of live vaccinations on immunosuppressive therapy in patients with immunemediated inflammatory diseases, solid organ transplantation or after bonemarrow transplantation - a systematic review of randomized trials, observational studies and case reports. Vaccine. 2017;35(9):1216-26.

34. Monath TP. Review of the risks and benefits of yellow fever vaccination including some new analyses. Expert Rev Vaccines. 2012;11(4):427-48.

35. Mota LM, Oliveira AC, Lima RA, Santos-Neto LL, Tauil PL. Vaccination against yellow fever among patients on immunosuppressors with diagnoses of rheumatic diseases. Rev Soc Bras Med Trop. 2009;42(1):23-7.

36. Higgins JPTGS. Cochrane handbook for systematic reviews of interventions, vol. Version 5.1.0: Cochrane Colaborations; 2011.

37. The Newcastle-Ottawa Scale (NOS) for assessing the quality of nonrandomised studies in meta-analyses [http://www.ohri.ca/programs/ clinical_epidemiology/oxford.asp]. Accessed Dec 2018. 
38. Guyatt GH, Oxman AD, Vist GE, Kunz R, Falck-Ytter Y, Alonso-Coello P, et al. GRADE: an emerging consensus on rating quality of evidence and strength of recommendations. BMJ. 2008;336(7650):924-6.

39. Howick J. Cl, Glasziou P, Greenhalgh T, Heneghan C, Liberati A, Moschetti I, OCEBM Levels of Evidence Working Group et al. "The Oxford Levels of Evidence 2". . In.: Oxford Centre for Evidence-Based Medicine; 2011

40. McMillan SS, King M, Tully MP. How to use the nominal group and Delphi techniques. Int J Clin Pharm. 2016;38(3):655-62.

41. Wieten RW, Goorhuis A, Jonker EFF, de Bree GJ, de Visser AW, van Genderen PJJ, et al. 17D yellow fever vaccine elicits comparable long-term immune responses in healthy individuals and immune-compromised patients. J Inf Secur. 2016;72(6):713-22.

42. Wieten RW, Jonker EF, Pieren DK, Hodiamont CJ, van Thiel PP, van Gorp EC, et al. Comparison of the PRNT and an immune fluorescence assay in yellow fever vaccinees receiving immunosuppressive medication. Vaccine. 2016; 34(10):1247-51.

43. Ferreira CC, Campi-Azevedo ACV, Peruhype-Magalhães V, Freire LC, Albuquerque CP, Muniza LF, et al. Imunidade vacinal antiamarílica em pacientes com artrite reumatoide. Rev BrasReum. 57:381.

44. Scheinberg M, Guedes-Barbosa LS, Mangueira C, Rosseto EA, Mota L. Yellow fever revaccination during infliximab therapy. Arthritis Care Res (Hoboken). 2010;62(6):896-8.

45. Oliveira AC, Mota LM, Santos-Neto LL, Simoes M, Martins-Filho OA, Tauil PL. Seroconversion in patients with rheumatic diseases treated with immunomodulators or immunosuppressants, who were inadvertently revaccinated against yellow fever. Arthritis Rheumatol. 2015;67(2):582-3.

46. Valim V, Gouveia SA, de Lima SMB, Azevedo ACC, Carvalho AT, Pascoal VPM, et al. Eficácia e segurança da vacinação anti-amarílica a curto e longo prazo em pacientes com doenças reumáticas imunomediadas em tratamento. Rev Bras Reumatol. 2017;57:S 52-3.

47. Lira KLL, Balarini L, de Lima SMB, Azevedo ACC, de Carvalho AT, Paschoal VPM, et al. Vacinação anti-amarílica em pacientes com doenças reumáticas imunomediadas: análise retrospectiva. Rev Bras Reumat. 2017:57:S69.

48. Kerneis S, Launay $O$, Ancelle $T$, lordache L, Naneix-Laroche $V$, Mechai $F$, et al. Safety and immunogenicity of yellow fever 17D vaccine in adults receiving systemic corticosteroid therapy: an observational cohort study. Arthritis Care Res (Hoboken). 2013;65(9):1522-8.

49. Nash ER, Brand M, Chalkias S. Yellow fever vaccination of a primary Vaccinee during adalimumab therapy. J Travel Med. 2015;22(4):279-81.

50. Charles C, Gafni A, Whelan T. Shared decision-making in the medical encounter: what does it mean? (or it takes at least two to tango). Soc Sci Med. 1997:44(5):681-92.

51. de Menezes Martins R, Fernandes Leal Mda L, Homma A. Serious adverse events associated with yellow fever vaccine. Hum Vaccin Immunother. 2015; 11(9):2183-7.

52. Lindsey NP, Rabe IB, Miller ER, Fischer M, Staples JE. Adverse event reports following yellow fever vaccination, 2007-13. J Travel Med. 2016;23(5).

53. McNeil MM, Li R, Pickering S, Real TM, Smith PJ, Pemberton MR. Who is unlikely to report adverse events after vaccinations to the vaccine adverse event reporting system (VAERS)? Vaccine. 2013;31(24):2673-9.

54. Tafuri S, Gallone MS, Calabrese G, Germinario C. Adverse events following immunization: is this time for the use of WHO causality assessment? Expert Rev Vaccines. 2015;14(5):625-7.

55. Tozzi AE, Asturias El, Balakrishnan MR, Halsey NA, Law B, Zuber PL. Assessment of causality of individual adverse events following immunization (AEFI): a WHO tool for global use. Vaccine. 2013;31(44):5041-6.

56. Biscayart C, Carrega ME, Sagradini S, Gentile A, Stecher D, Orduna T, et al. Yellow fever vaccine-associated adverse events following extensive immunization in Argentina. Vaccine. 2014;32(11):1266-72.

57. Cottin P, Niedrig M, Domingo C. Safety profile of the yellow fever vaccine Stamaril(R): a 17-year review. Expert Rev Vaccines. 2013;12(11):1351-68.

58. Khromava AY, Eidex RB, Weld LH, Kohl KS, Bradshaw RD, Chen RT, et al. Yellow fever vaccine: an updated assessment of advanced age as a risk factor for serious adverse events. Vaccine. 2005;23(25):3256-63.

59. Kitchener S. Viscerotropic and neurotropic disease following vaccination with the 17D yellow fever vaccine, ARILVAX. Vaccine. 2004;22(17-18):2103-5.

60. Rafferty E, Duclos P, Yactayo S, Schuster M. Risk of yellow fever vaccineassociated viscerotropic disease among the elderly: a systematic review. Vaccine. 2013;31(49):5798-805.
61. Thomas RE, Lorenzetti DL, Spragins W, Jackson D, Williamson T. The safety of yellow fever vaccine 17D or 17DD in children, pregnant women, HIV+ individuals, and older persons: systematic review. Am J Trop Med Hyg. 2012; 86(2):359-72.

62. Thomas RE, Lorenzetti DL, Spragins W, Jackson D, Williamson T. Active and passive surveillance of yellow fever vaccine 17D or 17DD-associated serious adverse events: systematic review. Vaccine. 2011;29(28):4544-55.

63. Caplan A, Fett N, Rosenbach M, Werth VP, Micheletti RG. Prevention and management of glucocorticoid-induced side effects: a comprehensive review: Infectious complications and vaccination recommendations. J Am Acad Dermatol. 2017;76(2):191-8.

64. Ekenberg C, Friis-Moller N, Ulstrup T, Aalykke C. Inadvertent yellow fever vaccination of a patient with Crohn's disease treated with infliximab and methotrexate. BMJ Case Rep. 2016;2016. https://doi.org/10.1136/bcr-2016-215403.

65. Lopez A, Mariette X, Bachelez H, Belot A, Bonnotte B, Hachulla E, et al. Vaccination recommendations for the adult immunosuppressed patient: a systematic review and comprehensive field synopsis. J Autoimmun. 2017;80:10-27.

66. Ruddel J, Schleenvoigt BT, Schuler E, Schmidt C, Pletz MW, Stallmach A. Yellow fever vaccination during treatment with infliximab in a patient with ulcerative colitis: a case report. Z Gastroenterol. 2016;54(9):1081-4.

67. Tarazona B, Diaz-Menendez M, Mato Chain G. International travelers receiving pharmacological immunosuppression: challenges and opportunities. Med Clin (Barc). 2017.

68. Brenol CV, da Mota LM, Cruz BA, Pileggi GS, Pereira IA, Rezende LS, et al. 2012 Brazilian Society of Rheumatology Consensus on vaccination of patients with rheumatoid arthritis. Rev Bras Reumatol. 2013;53(1):4-23.

69. Cetron MS, Marfin AA, Julian KG, Gubler DJ, Sharp DJ, Barwick RS, et al. Yellow fever vaccine. Recommendations of the advisory committee on immunization practices (ACIP), 2002. MMWR Recomm Rep. 2002;51(RR-17): 1-11 quiz CE11-14.

70. Rubin LG, Levin MJ, Ljungman P, Davies EG, Avery R, Tomblyn M, et al. 2013 IDSA clinical practice guideline for vaccination of the immunocompromised host. Clin Infect Dis. 2014;58(3):309-18.

71. Domingo C, Yactayo S, Agbenu E, Demanou M, Schulz AR, Daskalow K, Niedrig M. Detection of yellow fever 17D genome in urine. J Clin Microbiol. 2011:49(2):760-2.

72. CDC. Transfusion-related transmission of yellow fever vaccine virus-California. MMWR Morb Mortal Wkly Rep 2010. 2009;59(2):34-7.

73. CDC. Transmission of yellow fever vaccine virus through breast-feeding Brazil. MMWR Morb Mortal Wkly Rep 2010. 2009;59(5):130-2.

74. Kuhn S, Twele-Montecinos L, MacDonald J, Webster P, Law B. Case report: probable transmission of vaccine strain of yellow fever virus to an infant via breast milk. CMAJ. 2011;183(4):E243-5.

75. Stiggelbout AM, Pieterse AH, De Haes JC. Shared decision making: concepts, evidence, and practice. Patient Educ Couns. 2015;98(10):1172-9.

\section{Ready to submit your research? Choose BMC and benefit from:}

- fast, convenient online submission

- thorough peer review by experienced researchers in your field

- rapid publication on acceptance

- support for research data, including large and complex data types

- gold Open Access which fosters wider collaboration and increased citations

- maximum visibility for your research: over $100 \mathrm{M}$ website views per year

At BMC, research is always in progress.

Learn more biomedcentral.com/submissions 